\title{
Prenatal Exposure to Nicotine Impairs Performance of the 5-Choice Serial Reaction Time Task in Adult Rats
}

\author{
Tomasz Schneider*,', Nicholas llott ${ }^{2}$, Giovana Brolese ${ }^{3}$, Lisiane Bizarro ${ }^{3}$, Philip JE Asherson ${ }^{2}$ and \\ Ian P Stolerman' \\ 'Section of Behavioural Pharmacology, Institute of Psychiatry P049, King's College London, London, UK; ${ }^{2}$ MRC Social Genetic and Developmental \\ Psychiatry, Institute of Psychiatry P080, King's College London, London, UK; ${ }^{3}$ Departamento de Psicologia do Desenvolvimento e da \\ Personalidade, Instituto de Psicologia, Universidade Federal do Rio Grande do Sul, Porto Alegre-RS, Brazil
}

\begin{abstract}
Cigarette smoking is associated with a wide variety of adverse reproductive outcomes, including increased infant mortality and decreased birth weight. Prenatal exposure to tobacco smoke, of which nicotine is a major teratogenic component, has also been linked to the acceleration of the risk for different psychiatric disorders, including conduct disorder and attention deficit hyperactivity disorder (ADHD). Whether this increased risk is influenced by the direct effects of gestational nicotine exposure on the developing fetus remains uncertain. In this study we provide experimental evidence for the effects of prenatal nicotine exposure on measures of attention and impulsivity in adult male rats. Offspring of females exposed during pregnancy to $0.06 \mathrm{mg} / \mathrm{ml}$ nicotine solution as the only source of water (daily consumption: $69.6 \pm 1.4 \mathrm{ml} / \mathrm{kg}$; nicotine blood level: $96.0 \pm 31.9 \mathrm{ng} / \mathrm{ml}$ ) had lower birth weight and delayed sensorimotor development measured by negative geotaxis, righting reflex, and grip strength. In the 5-choice serial reaction time test, adult rats showed increased numbers of anticipatory responses and omissions errors, more variable response times, and lower accuracy with evidence of delayed learning of the task demands when the I s stimulus duration was introduced. In contrast, prenatal nicotine exposure had no effect on exploratory locomotion or delay-discounting test. Prenatal nicotine exposure increased expression of the D5 dopamine receptor gene in the striatum, but did not change expression of other dopamine-related genes (DRD4, DATI, NR4A2, and TH) in either the striatum or the prefrontal cortex. These data suggest a direct effect of prenatal nicotine exposure on important aspects of attention, inhibitory control, or learning later in life.

Neuropsychopharmacology (20 I I) 36, I I |4-I I25; doi: I0. I038/npp.20 I0.249; published online 2 February 20 I I
\end{abstract}

Keywords: nicotine; gestation; attention; impulsivity; dopamine system; ADHD

\section{INTRODUCTION}

Cigarette smoking is associated with a wide variety of adverse reproductive outcomes (Jauniaux and Burton, 2007), including increased infant mortality and decreased birth weight (Ernst et al, 2001; Winzer-Serhan, 2008). Prenatal exposure to nicotine, a major teratogenic component of tobacco, modulates neurotransmitter release, gene expression, neuronal outgrowth, cell survival, and synapse formation and maturation (Dwyer et al, 2008); and has also been linked to increased risk for childhood onset psychiatric disorders including attention deficit hyperactivity disorder (ADHD) (for review, see Pauly and Slotkin, 2008; Cornelius and Day, 2009). Recent literature suggests that the

*Correspondence: Dr T Schneider, Experimental Psychology, University of Oxford, South Parks Road, Oxford OXI 3UD, UK, Tel: + 441865 27|367, Fax: + 441865310447

E-mail: tomasz.schneider@psy.ox.ac.uk

Received 3 June 2010; revised 8 December 2010; accepted 8 December 2010 association with ADHD might be mediated by genetic effects rather than the direct toxic effects of nicotine (Thapar et al, 2009; D'Onofrio et al, 2008), but this has yet to be evaluated in an animal model.

ADHD is characterized by developmentally inappropriate and impairing levels of inattentive, hyperactive, and impulsive behaviors (Kuntsi et al, 2006) affecting 5\% of children (Polanczyk et al, 2007) and persisting into adult life in $\sim 65 \%$ of cases (Faraone et al, 2006). Heritability for ADHD is $\sim 76 \%$ (Faraone et al, 2005). Candidate gene studies have identified associations with genetic variants within or close to dopamine (DA) system genes including the D4 and D5 receptor genes (Li et al, 2006). Other DA system genes potentially associated with ADHD include the D1 receptor (DRD1; Misener et al, 2004), the DA transporter (DAT1; Asherson et al, 2007), and the DA-related intracellular transcription factor (NR4A2; Smith et al, 2005). More recently, rare copy number variants $>500 \mathrm{~kb}$ were found to be over-represented in ADHD cases compared with controls, implicating neurodevelopmental processes in the etiology of ADHD (Williams et al, 2010). 
A range of neuropsychological performance deficits is associated with ADHD, although none have been unequivocally implicated in the etiology of ADHD symptoms (Johnson et al, 2009). Furthermore, there is considerable heterogeneity in the pattern of associated cognitive deficits, leading to contemporary models of ADHD that emphasize the role of two or more independent processes (Johnson et al, 2009; Kuntsi et al, 2010). Twin studies find partially overlapping etiological influences on the two core symptom domains of inattention and hyperactivity-impulsivity (McLoughlin et al, 2007). Overall, these findings indicate that ADHD is a heterogeneous condition with distinct etiological influences conferring risk to different behavioral and neuropsychological components of the disorder.

Cognitive performance impairments are seen on tasks measuring response inhibition and sustained attention such as the continuous performance test (Johnson et al, 2009; Willcutt et al, 2005). Compared with healthy controls, individuals with ADHD make more errors of omission (index of sustained attention) and commission (index of response inhibition), and have slower and more variable response times thought to reflect impairments in arousal or cognitive-energetic processes (Epstein et al, 2001, 2003; Klein et al, 2006; Uebel et al, 2010; Andreou et al, 2007; Johnson et al, 2009). Cognitive performance deficits have also been observed in choice impulsivity measured as the tendency to choose small rewards sooner than larger rewards later (Marco et al, 2009; Paloyelis et al, 2009). The ADHD combined subtype has been linked to the tendency to discount rewards more steeply, although evidence to date is limited and somewhat inconsistent (Barkley et al, 2001; Scheres et al, 2006; Paloyelis et al, 2009).

Comparable aspects of cognitive performance can be measured in animals. Reaction time mean and variability, accuracy errors, omission errors, and anticipatory responses, thought to reflect processes related to attention and impulsivity, can be assessed with the 5-choice serial reaction time test (5-CSRTT); choice impulsivity can be assessed in delay-discounting paradigms (Winstanley et al, 2006). These aspects of cognitive function have yet to be studied in animals prenatally exposed to nicotine, although other experimental measures have been investigated. Identified effects include intolerance to hypoxia (Slotkin et al, 1995), hyperactivity (Tizabi et al, 1997; Pauly et al, 2004), cognitive impairments (choice accuracy in spatial spontaneous alteration: Levin et al, 1993; acquisition and retention of the avoidance behavior: Vaglenova et al, 2008; radial-arm maze choice accuracy: Sorenson et al, 1991), increased anxiety (Vaglenova et al, 2004), and delayed development and maturation (Peters and Ngan, 1982; Murrin et al, 1987; Schneider et al, 2010). However, these findings are not entirely consistent as some studies found no decrement in avoidance behavior and spatial learning (Bertolini et al, 1982; Paulson et al, 1993), as well as hypoactivity (LeSage et al, 2006). Prenatal nicotine exposure has also been found to produce alterations in the development of neurochemical markers for DA in offspring (Fung, 1989; Ribary and Lichtensteiger, 1989; Muneoka et al, 1999).

In this study we evaluate in an animal model whether prenatal nicotine exposure influences cognitive functions related to ADHD in adult life. In addition, maturational and developmental data were collected and the activity level in a novel environment was measured in adults. Because of the strong a priori hypothesis of altered DA regulation in ADHD, we also determined mRNA expression for markers of DA function in frontal cortex and striatum, the regions known to be involved in ADHD (Durston et al, 2010).

\section{SUBJECTS AND METHODS}

\section{Subjects}

Both male $(N=25)$ and female $(N=67)$ Lister hooded rats (Harlan Olac, Bicester, UK) were used. They were housed individually (except during mating) and had ad libitum access to food and drinking fluids (tap water or nicotine solutions). Females (224-303 $\mathrm{g}$ at the beginning of the study) were weighed three times during the week preceding the start of the experiment. The average weight was calculated for each rat. A total of 56 females were divided into two groups (NIC exposure, $n=19$, foster mothers, $n=37$ ) balanced according to their body weight. Nineteen of the foster mothers were randomly chosen for use as a control group for comparisons of pregnancy and litter characteristics. An additional group of females $(n=11)$ was used to assess nicotine blood levels in pregnant animals. The national and institutional guidelines for housing and treatment were followed. Animals were maintained in a temperature-controlled environment $\left(21 \pm 1{ }^{\circ} \mathrm{C}\right)$ at $50 \%$ humidity and on a 12-h light/dark cycle.

\section{Drug}

Nicotine bitartrate (Sigma, St Louis. MO) was dissolved in drinking water at varying concentrations. Nicotine-containing water was adjusted to the $\mathrm{pH}$ of drinking water $(\mathrm{pH}$ 7) with $0.001 \mathrm{~N} \mathrm{NaOH}$. Doses are presented as those of nicotine base.

\section{Nicotine Consumption and Nicotine Blood Level}

The procedure was based on the methods of Schneider et al (2010) with some modifications. In brief, 19 females were habituated to increasing concentrations of nicotine solution $(0.02,0.04$, and $0.06 \mathrm{mg} / \mathrm{ml})$ in tap water as the only source of fluid for 3 weeks before mating. The final concentration used was $0.06 \mathrm{mg} / \mathrm{ml}$. Females drinking $<10 \mathrm{ml}$ of nicotine solution per day had supplementary access to water. Nicotine treatment was terminated on the day that pups were delivered. The female used as foster mothers $(n=37)$ continued to receive tap water. The females $(n=11)$ used to evaluate nicotine blood levels during the second week of pregnancy were exposed to nicotine in an identical manner and nicotine concentrations were determined using tail vein blood and gas chromatography.

\section{Mating}

Females were controlled according to their estrous cycle. Females in proestrus and estrous were mated during the dark phase of the day at the beginning of the fourth week of nicotine exposure. Nicotine solution was not withheld 
before mating. The day on which a vaginal plug or spermatozoa were found in the vaginal smear was defined as gestational day 0 .

\section{Pregnancy}

Pregnant females from the nicotine and control groups were weighed twice weekly. A $0.06 \mathrm{mg} / \mathrm{ml}$ nicotine solution was used throughout pregnancy and its consumption was assessed daily. Rats drinking $<10 \mathrm{ml}$ of nicotine solution on any particular day were given access to tap water for $3 \mathrm{~min}$. Food consumption was evaluated three times a week.

\section{Birth Measures}

All dams were checked twice daily (before 0800 and after 1630 hours) starting a few days before delivery. Deliveries completed by 0800 hours were assigned to postnatal day 1 (PND1). Pups born later that day were assigned to PND1 on the following morning. Litters were examined on PND1 for obvious morphological anomalies (eg, missing digits, facial malformations, and so on), sexed by relative anogenital distance, and, in the case of litters with $>8$ offspring, culled randomly to eight pups with equal numbers of males and females per litter whenever possible. Both nicotine-exposed and control litters were cross-fostered to nonexposed foster mothers within $24 \mathrm{~h}$ after birth and the pups were evaluated throughout the lactation period in terms of reflex development and neuromuscular maturation. Tests were selected from standard neurobehavioral developmental test batteries (Adams, 1986).

\section{Developmental Milestones}

In all, 14 control litters (53 males) and 8 NIC-exposed litters (20 males) were used to assess development and maturation in offspring. The dam was first removed from the home cage and specific tests measuring reflex development, motor coordination, and muscle strength were applied to the offspring. All testing was conducted between 0900 and 1600 hours.

To assess righting reflex, each pup was given two successive trials per day from PND 2 to 5, and the time from being placed in a supine position until it righted itself onto all four feet was recorded. The cutoff time was $30 \mathrm{~s}$. Surface righting reflects the development of labyrinthine and body righting mechanisms as well as vestibular function and motor development.

Negative geotaxis was observed daily from PND7 to PND10; pups were timed for completing a $180^{\circ}$ turn within $30 \mathrm{~s}$ when placed in a head-down position on a $25^{\circ}$ inclined wooden surface. Rats were given two consecutive trials per day and the mean was calculated. Negative geotaxis reflects vestibular function, motor development, and activity.

Forelimb grip strength was assessed on PND17. A steel wire $(20 \mathrm{~cm}$ long and $\sim 0.3 \mathrm{~cm}$ thick) was supported between two poles of wood $25 \mathrm{~cm}$ above the table covered with soft towels. The latency to fall off the wire grasped by both forepaws was measured with a maximum time of $20 \mathrm{~s}$ and is a measure of muscle strength.

\section{Maturational Milestones}

Pups from each litter were weighed on PND 1, 5, 10, 15, and 20 . The emergence of physical maturation landmarks were noted, including pinnae detachment (PND3), incisor eruption (PND 7-10), fur appearance (PND9), and eye opening (PND12). Eyes were recorded as open only when both eyes were open.

\section{Tests in Adulthood}

Tests in adulthood were conducted on groups of 10 (NIC) to 12 (Con) animals coming from 8 (NIC) and 12 (Con) litters.

\section{Locomotor Activity}

The number of cage crosses was assessed in 2-month old animals during a 60-min test session in photocell activity cages measuring $30 \times 30 \times 30 \mathrm{~cm}$ (Schneider et al, 2010). The animals had no previous exposure to the cages.

\section{5-CSRTT}

Aluminum operant conditioning chambers (Cenes, Cambridge, UK) were illuminated by house lights and housed in ventilated enclosures. The curved rear wall of each chamber contained five square holes. At the entrance of each hole, a photocell monitored interruptions of an infrared-light beam and at the rear there was a green light-emitting diode. A tray for delivering food pellets was located in the opposite wall, equidistant from each aperture.

The training phases of the experiments were based on procedures described elsewhere (Hahn et al, 2002). A total of 22 adult rats $(\mathrm{NIC}=10, \mathrm{Con}=12)$ aged 3 months were assessed in the 5-CSRTT. They were housed singly 1 week before starting the 5-CSRTT. The mean weight of each animal was calculated as the average of the three weights from that week. The start point for each individual rat on the growth curve was identified and the body weight of each rat was reduced to $85 \%$ of its free-feeding weight by restricting the amount of food given during the following week. The experiment started on the fourth day of food restriction. Training was initiated by habituation to the chamber and magazine training, followed by attentional training beginning with response holes illuminated for $10 \mathrm{~s}$ (stimulus duration), followed by the introduction of progressively more demanding task parameters (Table 1 ). In the final stage of training, a stimulus light in a randomly chosen hole was illuminated for $1 \mathrm{~s}$. If a subject nose-poked into a hole while it was illuminated or within $5 \mathrm{~s}$ after the light had terminated (limited hold), a $45 \mathrm{mg}$ food pellet (BioServ, Frenchtown, NJ) was delivered into the food tray and a correct response was registered.

A response into any other hole during that time was recorded as an incorrect response and resulted in a 5-s time-out during which the house light was extinguished. A failure to respond before the end of the limited hold was registered as an omission error and had no programmed consequences until animals reached step 3 of the procedure, when a time-out of $5 \mathrm{~s}$ duration was introduced (Table 1).

The next trial was initiated immediately after a correct response was made or at the end of the time-out that 
Table I Consecutive Steps During 5-CSRTT Training

\begin{tabular}{lcccccc}
\hline Step & $\begin{array}{c}\text { Stimulus } \\
\text { duration (s) }\end{array}$ & $\begin{array}{c}\text { Limited } \\
\text { hold (s) }\end{array}$ & $\begin{array}{c}\text { Mean intertrial } \\
\text { interval (s) }\end{array}$ & $\begin{array}{c}\text { Incorrect } \\
\text { time-out (s) }\end{array}$ & $\begin{array}{c}\text { Anticipatory } \\
\text { time-out (s) }\end{array}$ & $\begin{array}{c}\text { Number of } \\
\text { sessions }\end{array}$ \\
\hline 1 & 10 & 10 & 5 & 0 & 0 & 9 \\
2 & 5 & 5 & 5 & 5 & 5 & 0 \\
3 & 5 & 5 & 5 & 5 & 3 & 3 \\
4 & 1 & 3 & 5 & 5 & 12 \\
\hline
\end{tabular}

followed an incorrect response. The mean duration of the intertrial interval (ITI) was $5 \mathrm{~s}$; individual ITIs varied randomly within the range of $0.625-9.375 \mathrm{~s}$. Responses during ITIs were recorded as anticipatory responses and resulted in a time-out of $3 \mathrm{~s}$ duration starting from step 3 of the procedure (responses during the time-outs were not counted as anticipatory responses). All training and test sessions lasted for $30 \mathrm{~min}$. Rats were advanced into consecutive experimental stages when their accuracy (percentage of correct responses) reached $70 \%$ and number of omissions was not $>25 \%$.

Several performance measures were recorded: percentage of correct responses (accuracy) $=100 \times$ (correct responses/ (correct + incorrect responses) as a measure of spatial attention; percentage of omission errors (omissions) $=$ $100 \times$ (omission errors/stimuli presented), reflecting attention but also influenced by the general rate of responding; latency of correct responses=the mean time between stimulus onset and a nose-poke in the correct hole; latency of incorrect responses $=$ the mean time between stimulus onset and a nose-poke in an incorrect hole; anticipatory responses as percentage of trials $=100 \times$ total number of responses in ITIs/number of trials, as a measure of impulsive responding; reinforcers earned, equal to absolute number of correct responses in a session, as a measure of overall success of task performance. A measure of the variability of correct response times was introduced. Sessions were divided into three periods of $10 \mathrm{~min}$ for each of which the mean latency was recorded. The measure of variability was the SD of the mean latencies for the three 10-min periods.

\section{Delay-Discounting Paradigm}

Standard experimental chambers (Campden Instruments, London, UK) were contained in sound-insulated, ventilated enclosures. The chambers were fitted with two retractable levers separated by a recess in which $45 \mathrm{mg}$ pellets of food could be presented. White noise was present at all times to mask external sounds. The experiments were controlled by programs written with the Arachnid system (Paul Fray, Cambridge, UK) running under RISC OS on Acorn computers.

A separate group of 22 adult rats $(\mathrm{NIC}=10$, Con $=12$ ) aged 3 months were assessed in the delay-discounting test. They were habituated to experimental chambers during two 30 min sessions with reward pellets being delivered every $30 \mathrm{~s}$. Training was conducted over three phases and was based on previously described experimental procedures (Winstanley et al, 2004). In the first phase, rats were trained to press the left or right levers on alternate sessions to receive a $45 \mathrm{mg}$ food pellet (BioServ). Each $30 \mathrm{~min}$ session consisted of 60 trials. Subjects were trained for four sessions until all earned at least 50 rewards per session. In the second phase, rats were trained in $45 \mathrm{~min}$ sessions divided into three blocks. During the first two blocks, 50 trials each, only one lever, either right or left, was presented. During the third block, two forced trials (only one lever presented) were followed by 48 free choice trials (two levers presented). The second phase lasted for 6 days until all animals had reached $0 \%$ of omissions on two consecutive days. During the third phase each rat had one lever designated as the 'immediate' delivery lever (one pellet) and one lever as the 'delay' delivery lever (5 pellets), with a delay of $2 \mathrm{~s}$. Each session consisted of 24 trials, divided into 3 blocks of 8 trials, with trials spaced apart by $100 \mathrm{~s}$. Each 8 -trial block began with 2 'forced' trials in which either the left or the right lever was presented in random order for every pair of trials, followed by 6 'choice' trials in which both levers were presented. Levers assignments were counterbalanced across groups. The third phase lasted for 4 days until all animals had reached $90 \%$ preference for delayed larger reward on two consecutive days.

The main delay-discounting procedure was identical to the one used in the third phase of training, except that the delay to the larger reward was increased daily according to the sequence of $2,6,18,36,48,54,60$, and 66 s. Choice ratios (delay-lever presses/total lever presses) were calculated for each rat at each delay using the choice trial responses (ie, excluding single lever trials) summed across the three consecutive blocks.

\section{Gene Expression Studies}

Sample preparation. A total of 10 rats aged 5 months from control $(n=10)$ and NIC $(n=10)$ groups were killed by decapitation and the brains were immediately dissected. The striatum and a $2-\mathrm{mm}$ slice from the frontal cortex were removed, snap frozen on dry ice, and stored at $-80{ }^{\circ} \mathrm{C}$ until RNA extraction. RNA was extracted using Qiagen AllPrep RNA/DNA minikits (Qiagen, Crawley, UK). During the extraction procedure, RNA columns were treated with RNase-free DNase1 to eliminate genomic DNA contamination. Purity of RNA samples was assessed via the 260/280wavelength ratio using a NanoDrop spectrophotometer. All ratios were of acceptable quality (RNA range; 1.88-2.38).

Quantitative measurement of gene expression using $q R T-P C R$. Housekeeping gene (HK) selection was performed using geNorm kits (PrimerDesign, Southampton, UK). 
Table 2 Primers Used for Amplification of Five Target Genes

\begin{tabular}{|c|c|c|c|}
\hline Gene & Sense primer $\left(5^{\prime} \rightarrow 3^{\prime}\right)$ & Antisense primer $\left(5^{\prime} \rightarrow 3^{\prime}\right)$ & Product length (bp) \\
\hline Th & CCCTACCAAGATCAAACCTACC & CTGGATACGAGAGGCATAGTTC & 96 \\
\hline$N R 4 A 2$ & СТTCACAACTTCCACCACCAGAACTA & GGGGCGACTGCTTAAAGGA & 103 \\
\hline DATI & TCCAGTTACAATAAGTTCACCAATAA & CGACGAAGCCAGAGGAGAA & 94 \\
\hline Drd4 & TATGTCAACAGTGCCCTCAAC & AGACATCAGCGGTTCTITCAG & 110 \\
\hline Drd5 & GGGAGAGGAGGAGGAGGAG & GGGGTGAGAGGTGAGATITG & 144 \\
\hline
\end{tabular}

Primers were designed and supplied by PrimerDesign.

The stability of 11 commonly used HK genes was assessed using $500 \mathrm{ng}$ total RNA from 4 samples of each group. Samples were first strand reverse transcribed in $20 \mu \mathrm{l}$ reactions using oligoT priming and Moloney murine leukemia virus (MMLV) reverse transcription (PrimerDesign). SYBR green chemistry was used to quantify HK mRNA following the manufacturer's guidelines for cycling conditions, with all samples run in duplicate (www.primerdesign. co.uk). GeNorm, a Visual Basic application tool in Excel, was used to statistically model the stability of the HK genes for accurate normalization of target genes. The geNorm output provides the user with the two most stably expressed HK genes, along with stability values for all genes analyzed. We chose three HK genes for normalization of target genes in each tissue: Cyc1, Mdh1, and Ywhaz for striatum and Cyc1, $M d h 1$, and Gapdh for frontal cortex.

Primers and PerfectProbe technology (PrimerDesign) were used to quantify five target genes; Th, Nr4a2, Slc6a3, Drd4, and Drd5, along with the three HK genes for each tissue. Primer sequences for target genes are given in Table 2. Total RNA was first strand cDNA synthesized in $20 \mu \mathrm{l}$ reactions using oligoT priming and MMLV reverse transcription; qRT-PCR reactions were performed in triplicate.

\section{Statistical Analysis}

Behavioral data were analyzed using one- or two-factor ANOVA followed by Bonferroni modified least significant difference test (LSD) for post hoc analysis. For maturational and developmental data, litter (only males) was used as the unit for statistical analysis. Thus, the data subjected to statistical analyses were means for entire litters rather than results for individual animals within litters. The 5-CSRTT percentage data for accuracy and omissions were arcsine transformed, and latency data were log transformed (Hahn et al, 2002). Spearman's rank correlation test was used to correlate measures obtained in the 5-CSRTT. For those variables assessed multiple times, age (PND) and day of training were used as repeated measures.

Gene expression results (qRT-PCR data) were compared using the Mann-Whitney test. The Grubbs method was applied to identify outliers from triplicate samples (Burns et $a l, 2005)$ after which arithmetic means were taken across replicates and the comparative $\mathrm{Ct}$ method $(\Delta \Delta \mathrm{Ct})$ applied (Livak and Schmittgen, 2001). Animals were excluded from the analysis of all genes if they showed expression values that were $>2$ SD from the mean in a given group for at least two genes (one animal from control and two animals from NIC group). All tests of significance were performed at $\alpha=0.05$ using Unistat 5.6 (Unistat, London, UK). All data are presented as mean \pm SEM if not otherwise stated.

\section{RESULTS}

\section{Nicotine Exposure Before and During Pregnancy}

Three weeks of pre-exposure to increasing doses of nicotine as the only source of water resulted in decreased body weight before mating $(\mathrm{F}(1,25)=15.1, p<0.001)$. During the last week of habituation, when the final concentration of nicotine solution was used, both solution $(\mathrm{F}(1,25)=$ 109.2, $p<0.001)$ and food consumption $(\mathrm{F}(1,25)=5.29$, $p<0.05)$ per kg body weight were decreased in the nicotineexposed group. Lower body weight $(255.8 \pm 4.7$ vs $297.7 \pm 4.0 ; \mathrm{F}(1,25)=46.4, p<0.001)$ and decreased solution consumption $(69.6 \pm 1.4$ vs $146.8 \pm 2.5 \mathrm{ml} / \mathrm{kg} ; \mathrm{F}(1,25)=$ $71.7, p<0.001)$, but not decreased food consumption (65.1 +0.8 vs $67.1+0.9 \mathrm{~g} / \mathrm{kg} ; \mathrm{F}(1,25)=1.59$, NS), were also observed in pregnant animals exposed to nicotine.

\section{Nicotine Blood Levels}

The mean plasma nicotine blood level during the second week of pregnancy was $96.0 \pm 31.9 \mathrm{ng} / \mathrm{ml}$ (mean \pm SD). There was no difference in mean nicotine solution consumption per $\mathrm{kg}$ body weight per day between the groups of nicotine-exposed pregnant females used for nicotine blood tests or for offspring delivery $(67.9 \pm 8.9 \mathrm{vs}$ $69.6 \pm 1.4 \mathrm{ml} / \mathrm{kg}$, corresponding to $4.07 \pm 0.05$ vs $4.17 \pm$ $0.08 \mathrm{mg} / \mathrm{kg}$ of nicotine, respectively).

\section{Litter Characteristics}

There was no difference between control litters and those prenatally exposed to nicotine in any of the measures used: the number of live litters (11 cf 14), the percentage of live litters (57.9 cf 73.7), number of animals per litter $(5.9 \pm 0.6$ cf $5.7 \pm 0.8$ ), the numbers of females and males per litter ( $2.1 \pm 0.3 v s 3.0 \pm 0.5$ and $2.9 \pm 0.6$ vs $2.0 \pm 0.4$, respectively), and numbers of dead or malformed animals (1.36 $\pm 0.5 \mathrm{vs}$ $0.73 \pm 0.6)$.

\section{Postnatal Growth and Maturation}

Prenatal nicotine exposure had no effect on the body weight gain of the offspring $(\mathrm{F}(4,80)=1.51$, NS) but birth weights were lower in exposed animals (Figure 1a; $\mathrm{F}(1,20)=24.8$, $p<0.001)$. The other maturational measures used in this 

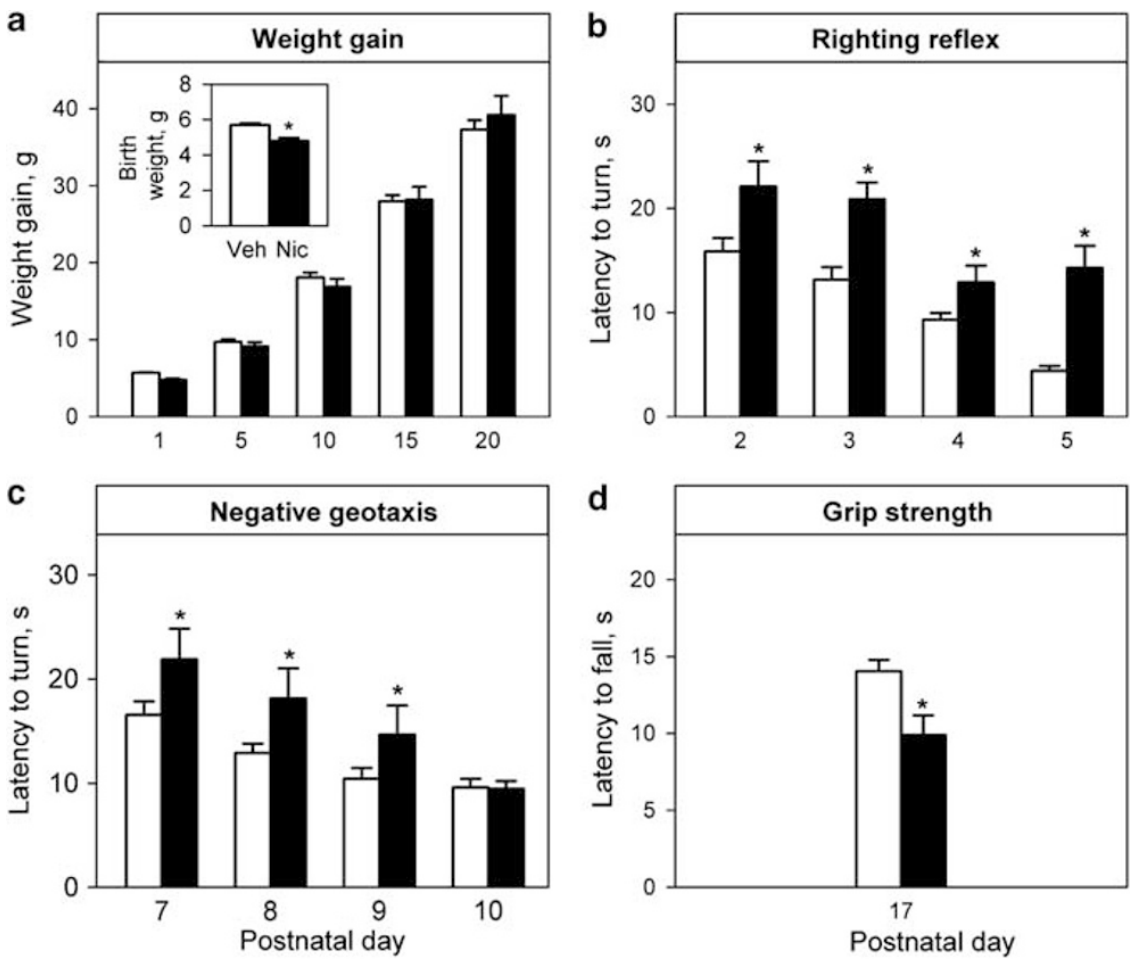

Figure I Decreased birth weight (a), impairment of motor coordination (b, c) and muscle strength (d) in male rats prenatally exposed to nicotine. Data are shown as means \pm SEM (white bars, controls, $n=14$; black bars, nicotine exposed, $n=8$ ). Litter was used as a unit for analysis. *p $<0.05$ from post hoc tests of between-group effects by least significance difference.

study (pinnae detachment, fur appearance, incisor eruption, and eye opening) did not differ between the groups.

\section{Neurobehavioral Development}

The ontogeny of the righting reflex was delayed in animals prenatally exposed to nicotine (Figure $1 \mathrm{~b} ; \mathrm{F}(1,20)=40.3$, $p<0.001)$. Rats in both groups showed decreased latencies to right themselves onto all four feet from a supine position over the consecutive sessions $(F(3,60)=27.2, p<0.001)$. There was no group $\times$ PND interaction.

Similarly, the ontogeny of negative geotaxis was significantly delayed in rats prenatally exposed to nicotine (Figure $1 \mathrm{c} ; \mathrm{F}(1,20)=5.92, p<0.03$ ). Both groups decreased the latencies to turn $180^{\circ}$ over the consecutive sessions $(\mathrm{F}(3,60)=15.8, p<0.001)$. There was no group and PND interaction.

Rats prenatally exposed to nicotine also showed decreased grip strength on PND17 (Figure 1d; $\mathrm{F}(1,20)=9.24$, $p<0.01)$.

\section{Locomotor Activity in Adulthood}

There was no difference between nicotine-exposed and control animals in the number of cage crosses during a 60 -min session ( $57.4 \pm 8.8$ vs $59.9 \pm 9.3$, respectively).

\section{5-CSRTT}

There was no difference between control and nicotineexposed animals during acquisition of the task when the duration of the visual stimuli was either 10 or $5 \mathrm{~s}$. However, at the final stage when a 1-s stimulus duration was used, the performance of rats prenatally exposed to nicotine was compromised (Figure 2). Under this condition, adult rats prenatally exposed to nicotine exhibited: decreased accuracy $(F(1,20)=6.25, \quad p<0.03$; Figure 2a); smaller numbers of reinforcers earned $(\mathrm{F}(1,20)=6.11, p<0.03$; Figure 2c); and an increased percentage of anticipatory responses $(\mathrm{F}(1,20)=22, p<0.0001$; Figure $2 \mathrm{~d})$. There was also a trend toward increased omission errors $(\mathrm{F}(1,20)=3.02, p<0.1)$ and a significant group $\times$ day interaction $(\mathrm{F}(11,220)=1.90, p<0.05$; Figure $2 \mathrm{~b})$; the numbers of omission errors were increased during the first 2 days after introduction of the 1-s stimulus duration and on day 5. There was no group $\times$ day interaction for anticipatory responses $(\mathrm{F}(11,220)=1.81, p=0.06)$, accuracy $(\mathrm{F}(11,220)=1.59, p=0.1)$, and the number of reinforcers earned $(\mathrm{F}(11,220)=1.54, p=0.1)$, and there was no between-group difference in the speed of responding for either correct or incorrect responses $(\mathrm{F}(1,11)=3.31$, $p=0.1$ and $\mathrm{F}(1,11)=0.04, p=0.8$, respectively). There was a significant effect of day for all variables shown in Figure 2 (smallest $\mathrm{F}(11,220)=5.38, p<0.001)$ that was attributable to a progressive improvement of performance over the 12 days for accuracy, numbers of reinforcers, and anticipations; only the pattern of omission errors did not show an orderly relationship over days.

Rats prenatally exposed to nicotine showed signs of an increased variability of response times for correct responses (group: $\mathrm{F}(1,20)=3.49, p<0.07$; group $\times$ day interaction: $\mathrm{F}(11,220)=2.0, p<0.03$; Figure 3 ) with significantly increased variability on days 3 and 10 . The variability of response times for correct responses was 

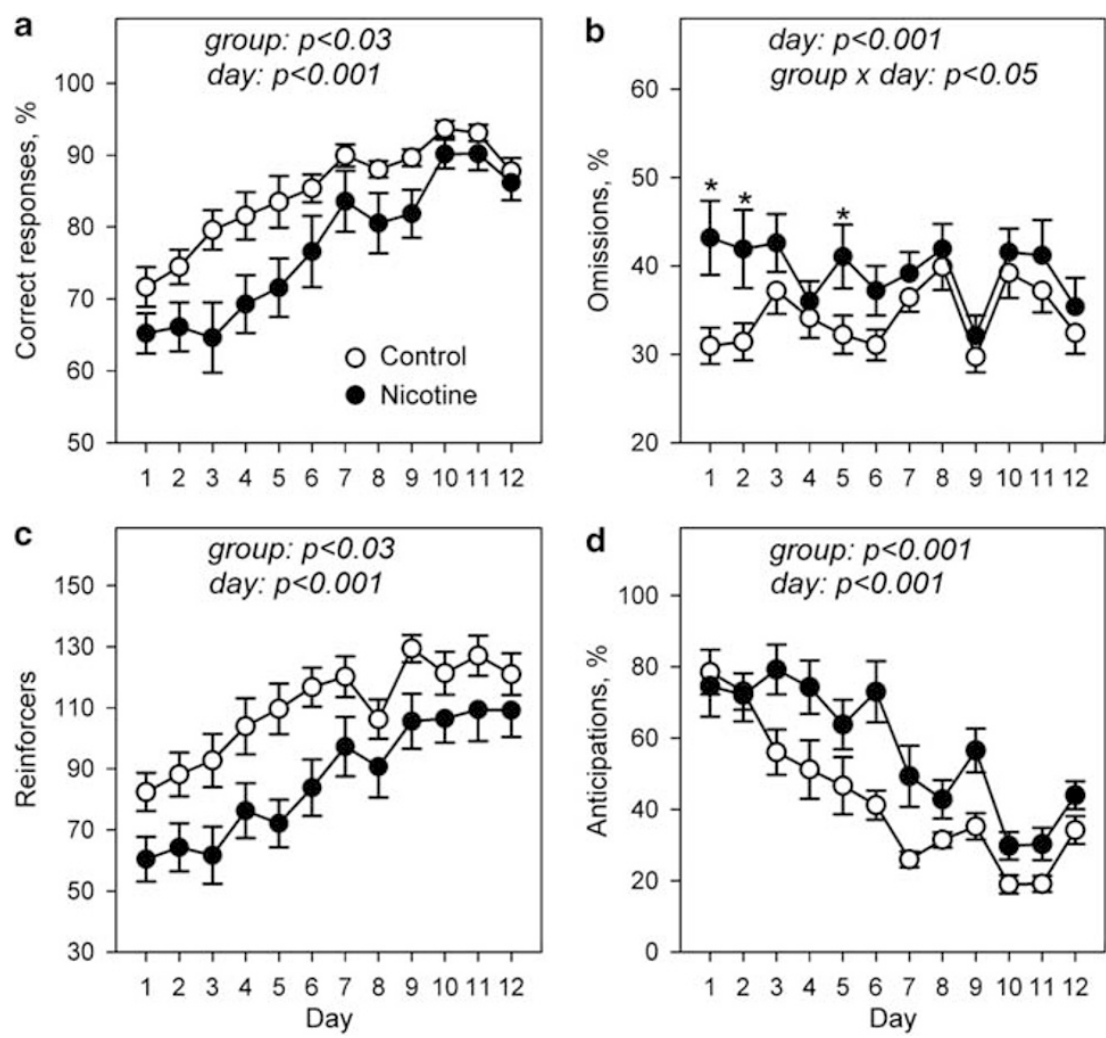

Figure 2 Impairments in attentional performance in the 5-CSRTT in adult control rats $(n=12)$ and in nicotine-exposed rats $(n=10)$. Data are shown for percentage correct responses (a), number of anticipations, percentage omission errors (b), number of reinforcers earned (c), and percentage numbers of anticipatory responses (d) for 12 days when a I-s stimulus duration was used (means \pm SEM).

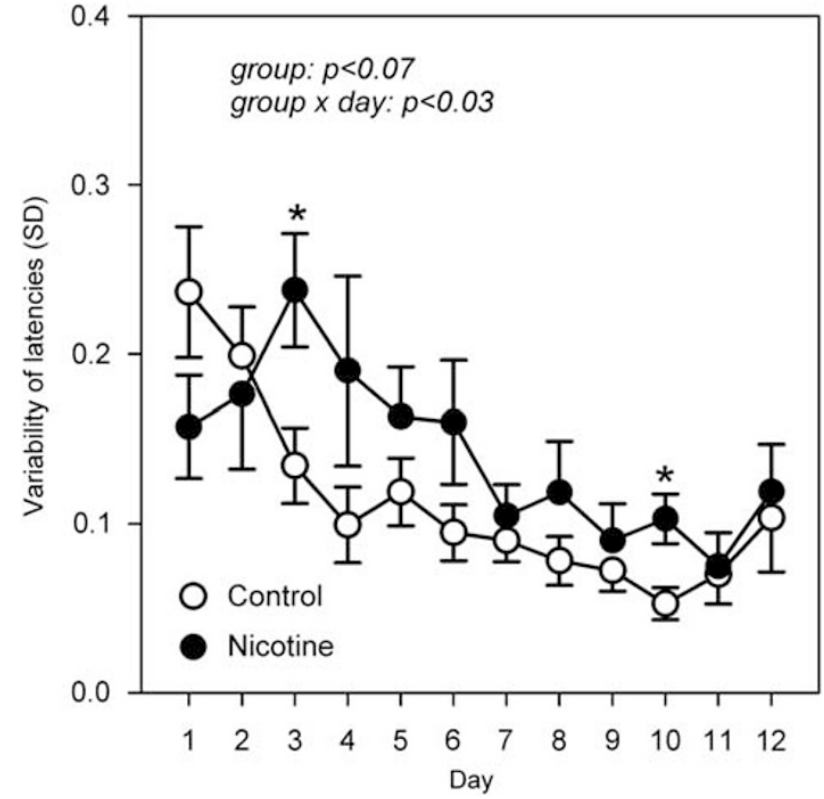

Figure 3 Increased intraindividual variability (SD) of response times for correct responses in the 5-CSRTT in adult control and nicotine-exposed rats. The SD of latency for correct responses is shown as means \pm SEM. Other details as for Figure 2.

negatively correlated with accuracy $(r=-0.52, p<0.001)$ and positively correlated with anticipation rate $(r=0.42$, $p<0.001)$.

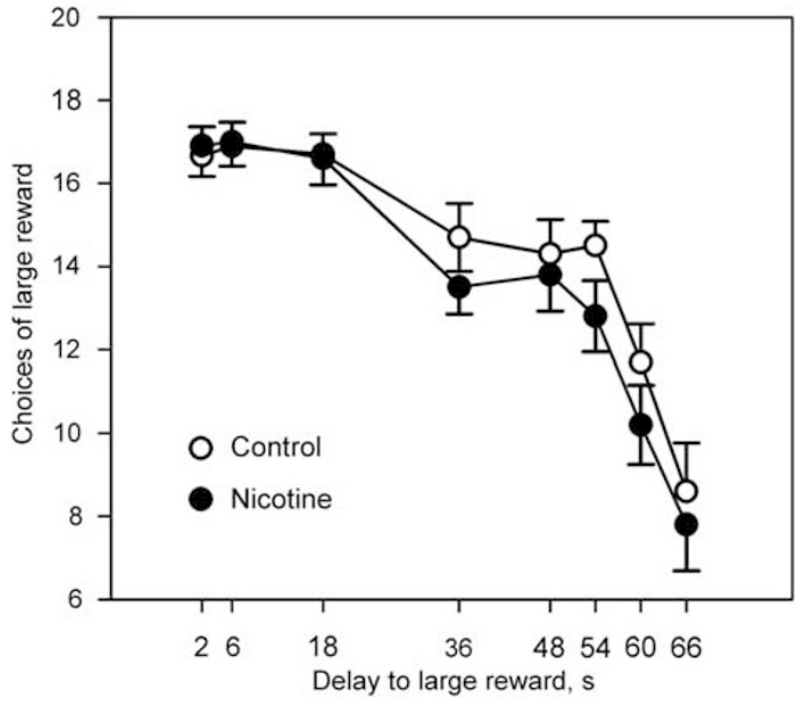

Figure 4 Lack of effect of gestational exposure to nicotine on delaydiscounting (controls, $n=12$; nicotine exposed, $n=0$ ). Data are shown as means \pm SEM.

\section{Delay-Discounting Test}

Both nicotine-exposed and control animals chose the large reward on almost every trial when the delay to the large reward was $2 \mathrm{~s}$ (Figure 4). As the delay to the large reward increased, the preference of both groups of rats shifted toward the smaller but more immediate reward 
a
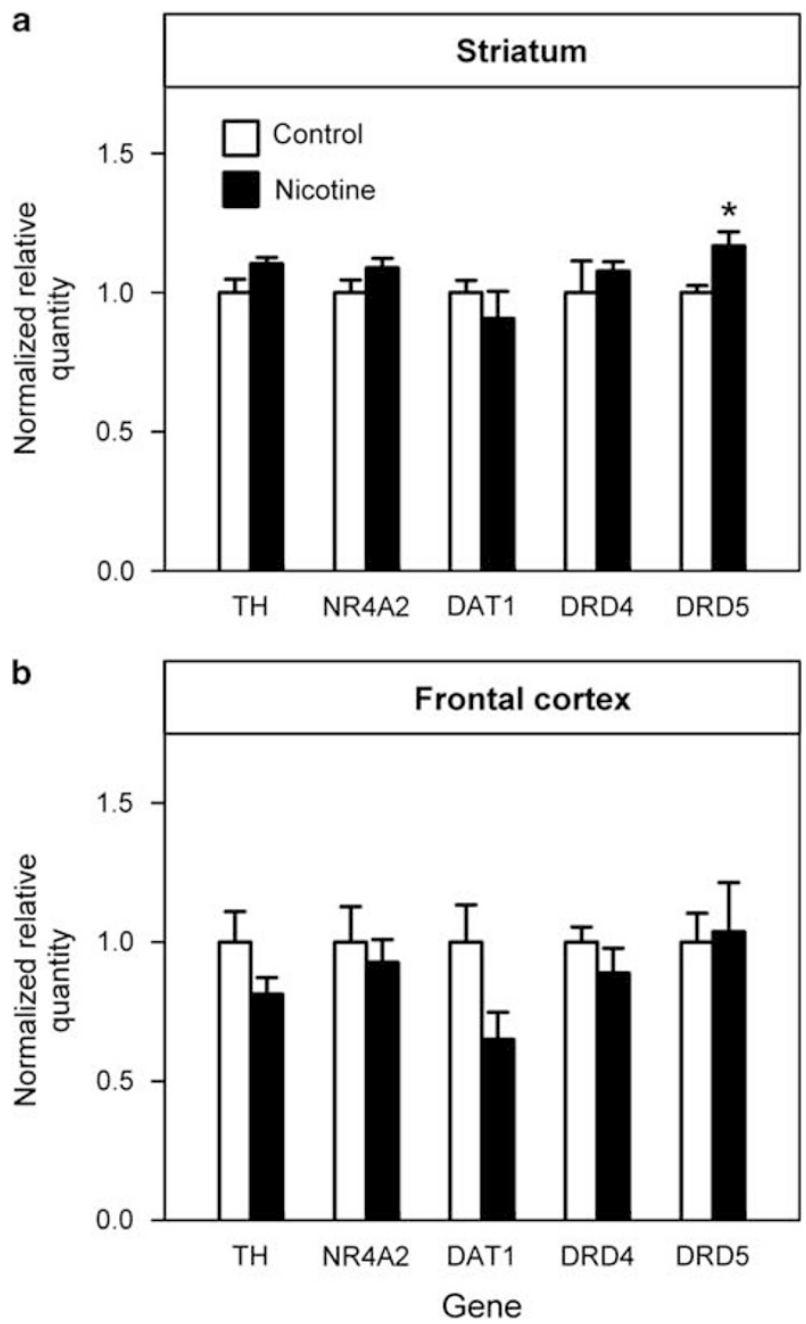

Figure 5 Effects of prenatal exposure to nicotine on the expression of dopamine-related genes of adult rats; striatum (a), prefrontal cortex (b). Data obtained by RT-PCR are shown as means \pm SEM for control $(n=9$; white bars) and nicotine-exposed $(n=8$, black bars) animals. *Mann-Whitney U-test results significant at least at $P<0.05$.

(delay: $\mathrm{F}(7,18)=43.1, p<0.001)$; however, there was no significant effect of nicotine exposure on choice behavior at different delays (group: $\mathrm{F}(1,18)=1.29$, NS; delay $\times$ group: $\mathrm{F}(7,129)=0.73$, NS).

\section{Gene Expression}

There was a significant increase in the expression of DRD5 mRNA in the striatum of animals prenatally exposed to nicotine $(U=8, p<0.006)$. There were no further differences between the two groups for any genes in either tissue (Figure $5 \mathrm{a}$ and $\mathrm{b}$ ).

\section{DISCUSSION}

In this study we present the first experimental evidence of a link between prenatal nicotine exposure and cognitive performance deficits on the 5-CSRTT in adult rats. Following gestational exposure to nicotine, the offspring were found not only to have lower birth weight and delayed sensorimotor development, but also to be impaired during adulthood with respect to several measures of performance of the 5-CSRTT. In contrast, nicotine exposure had no effect on the locomotor activity of adult rats in a novel environment or on impulsive choice in the delay-discounting test.

\section{Nicotine Exposure and Litter Characteristics}

The daily nicotine consumption of the pregnant mothers of $4.61 \pm 0.54 \mathrm{mg} / \mathrm{kg}$ resulted in nicotine blood levels of $96 \pm 31.9 \mathrm{ng} / \mathrm{ml}$, which is at the upper end of the dose range for heavy smokers (Benowitz et al, 2009). In line with previous animal studies (eg, Murrin et al, 1987; Schneider et al, 2010), females exposed to a nicotine solution as the only source of fluid during pregnancy showed decreased body weight gain and lower solution and food consumption, although the latter was not significant in the present study. The implications of the reduced weights of the nicotineexposed mothers and decreased food and water consumption need further investigation. Prenatal exposure to nicotine had no effect on the number of live litters, litter size, numbers of males and females per litter, or the numbers of malformed or dead offspring, suggesting only mild teratogenicity of the nicotine dose regimen used in this study.

\section{Developmental Changes}

Birth weight was decreased by prenatal exposure to nicotine, although there was no difference in weight gain during development (Figure 1a). This was expected and is similar to the results of human studies (Eskenazi et al, 1995). The offspring of animals exposed to nicotine in utero consistently show lower birth weights (Paulson et al, 1993; Peters and Ngan, 1982; Schneider et al, 2010); and in humans, the direct impact of prenatal nicotine exposure on birth weight remains after controlling for maternal genetic influences (Thapar et al, 2009). The long-term significance of lower birth weight is still unclear, but studies in humans have found associations between low birth weight and longterm cognitive deficits (Hack, 2006; Gianni et al, 2007) and behavioral disorders including ADHD (Winzer-Serhan, 2008). Recent evidence from monozygotic twin pairs shows that low birth weight confers a direct risk of ADHD that is independent of genetic effects (Greven et al, 2010).

Other maturational measures used in this experiment (pinnae detachment, fur appearance, incisor eruption, and eye lid opening) were spared in offspring prenatally exposed to nicotine. In contrast, developmental measures were all compromised. Significant delay of the righting reflex and negative geotaxis, as well as a shorter latency to fall in the grip strength test, were observed in rats prenatally exposed to nicotine, suggesting impairment of motor coordination and muscle strength (Figure 1). Our results are in line with previous studies showing deficits in righting reflex and negative geotaxis in rats and mice exposed to similar doses of nicotine (Peters and Ngan, 1982; Ajarem and Ahmad, 1998; Schneider et al, 2010). The delay in attaining these skills is probably because of damage or poor development 
of the motor and vestibular systems of the brain, but this needs further study.

\section{Deficits in Tests of Attention and Impulsivity}

Previous studies have demonstrated deficits in learning and memory in adult rats prenatally exposed to nicotine (Vaglenova et al, 2008; Levin et al, 1993), whereas the present report investigates possible impairments in attention, impulsive responding, variability of reaction times, and delay discounting using the 5-CSRTT and delaydiscounting tasks.

The development of the 5-CSRTT for rats was initially stimulated by the need to understand, at a preclinical level, the nature of the deficits shown by children with ADHD and the effects of psychostimulant drugs such as methylphenidate (Robbins, 2002). The task is modeled after Leonard's 5-CSRTT used to study human attentional processes and is considered to have similarities with the continuous performance test of attention (Robbins, 2002). When stimulus duration in the 5-CSRTT is as short as $1 \mathrm{~s}$, the procedure is regarded as a means for assessing sustained attention rather than simply discriminated responding.

In the prenatal exposed nicotine group, we observed a trend $(p<0.1)$ in the rate of omission errors in the $1 \mathrm{~s}$ stimulus condition, which improved during the course of the 12 days of testing, with a significant group by day interaction $(p<0.05)$. The observed impairment therefore reflects a delayed ability to learn a task with a high attentional load, which could reflect a deficit of attentional processing or more general learning difficulties. However, the group $\times$ day interaction was significant only for omission errors and only in the $1 \mathrm{~s}$ stimulus condition, suggesting that the learning difficulty was restricted to a task condition that demanded high levels of sustained attention. This interpretation should be balanced by the possibility that the study might be underpowered to detect significant day by group interactions for the other variables, which would then indicate a more general learning difficulty.

In considering whether the pattern of increased omission errors in the 5-CSRTT is comparable with findings in ADHD, the study design with repeated daily measures needs to be taken into account. To the authors' knowledge, no comparable studies have been performed in ADHD with repeated daily measures, and hence it is not known whether performance in children and adults with ADHD would improve and catch up with the performance of healthy controls.

The other significant impairments that emerged in the $1 \mathrm{~s}$ stimulus condition, which did not show significant group $\times$ day interactions, included decreased accuracy, increased anticipatory responses, smaller number of earned rewards, and response time variability (RTV). Accuracy in the task is thought to represent processes related to sustained attention, whereas anticipatory responses during the intratrial periods are thought to reflect a form of impulsive responding. Neither of these measures has been widely adopted in ADHD research, and hence it is difficult to make direct comparisons. Accuracy is rarely included in ADHD studies because there are marked ceiling effects in equivalent human tasks such as the fast task (Andreou et al, 2007), with both cases and controls showing very low rates of accuracy errors. In contrast, anticipatory responses have been evaluated in a few studies and are found to be significantly increased in children with ADHD compared with healthy controls (Bedard et al, 2003; Wada et al, 2000).

The RTV in the rats correlated negatively with accuracy scores and positively with anticipatory responses, suggesting that a general deficit might underlie the pattern of findings that link RTV to changes in attention and anticipatory responses. However, the change in RTV in the rat model may not reflect the same processes that lead to increased RTV in human disorders such as ADHD. First, increased RTV in humans with ADHD occurs under slow unrewarded conditions and tend to normalize under rewarded conditions (Andreou et al, 2007; Uebel et al, 2010), whereas responses in the 5-CSRTT are rewarded. Second, the measure of RTV used in this study is the SD of data averaged across three 10-min periods, which is different from the trial-by-trial variability associated with ADHD (Klein et al, 2006).

In the delay-discounting task, which measures a specific aspect of choice impulsivity, there was no difference detected between nicotine-exposed and controls rats. Human research suggests an association between ADHD and performance on delay-discounting tasks in children, although this is not consistently found in all children with ADHD (Marco et al, 2009; Paloyelis et al, 2009) and has not been studied in adults with ADHD. The discrepancy in our findings between impulsive responding indexed by anticipatory responses in the 5-CSRTT and the delay-discounting test is not unexpected, because these measure entirely different aspects of impulsivity, consistent with the nonunitary nature of impulsive behavior in humans (Evenden, 1999; Moeller et al, 2001; McDonald et al, 2003; Patton et al, 1995) and animals (see Winstanley et al, 2006 for review).

In utero nicotine exposure has also been associated with 'hyperactivity' in humans as measured by a combined parental rating of restlessness, being fidgety, unable to settle, and easily distracted (Kotimaa et al, 2003), but no studies have used actigraph data. Overactivity in ADHD has been shown to be more pronounced under constant (habituated) and unstimulating conditions and to normalize in novel or stimulating environments (Antrop et al, 2000; Sagvolden et al, 1998). In this study we evaluated activity during a single activity test session, reflecting exploratory activity in a novel environment. Furthermore, the lack of effect of prenatal exposure to nicotine on exploratory locomotor activity in adult rats contrasts with some previous reports (Tizabi et al, 1997; Pauly et al, 2004; Ajarem and Ahmad, 1998), but agrees with others (LeSage et al, 2006; Romero and Chen, 2004). We did however observe increased locomotor activity after repeated testing of adolescent rats exposed prenatally to nicotine (Schneider et al, 2009), which accords better with the human literature on ADHD.

\section{Gene Expression Analysis}

The most probable direct effects of prenatal nicotine exposure would be on nicotinic acetylcholine (ACh) systems (Slotkin, 2004) but given the close anatomic association of the ACh and the DA systems, it is likely to have secondary effects on the DA system (Shea and Steiner, 2008). In this study we focused on the DA system because dysregulation of DA signaling has been clearly implicated in processes 
leading to deficits of attention and impulsive responding. Animal studies indicate that prenatal exposure to nicotine has lasting effects on behaviors regulated by DA, including locomotor activity, stereotypy, and drug self-administration (Tizabi et al, 1997; Ajarem and Ahmad, 1998; Levin et al, 2006; Paz et al, 2007; Franke et al, 2008). This study looked for long-lasting effects of prenatal nicotine exposure on quantitative expression of the DA-related genes NR4A2, TH, $D A T 1, D R D 4$, and $D R D 5$ that index DA regulatory function or have been reported to be associated with ADHD in genetic association studies (Waldman and Gizer, 2006; Gizer et al, 2009). We investigated gene expression in the rat striatum and frontal cortex because cortico-striatal pathways have been strongly implicated in ADHD (Castellanos, 2001) as well as attention and impulsive decision-making processes (Muir et al, 1996; Rogers et al, 2001; Cardinal, 2006; Winstanley et al, 2006).

There was little evidence for expression differences between the two groups for any of the genes studied in either tissue, although there was a small increase in DRD5 mRNA expression in the striatum of nicotine-exposed animals. Whether such a small difference is capable of influencing behavior remains an open question. Nevertheless, human studies suggest that DRD5 might be an important gene for ADHD, with evidence for the association of a specific genetic marker close to the DRD5 gene providing some of the strongest evidence for association with ADHD in children $(\mathrm{OR}=1.34,95 \%$ CI 1.21-1.50, $\left.p=8 \times 10^{-8}\right)$ in a meta-analysis of nine independent studies (Li et al, 2006). Furthermore, the allele-specific association was recently replicated in a sample of adult patients with ADHD (Johansson et al, 2008). Interestingly, the DRD5 repeat polymorphism was reported to be associated with lower performance scores on the TOVA continuous performance test in ADHD patients and their parents (Manor et al, 2004).

\section{Study Limitations}

This study has two main limitations. First, the possible teratogenic effects of prenatal exposure to nicotine cannot be clearly distinguished from the potential effects of dehydration and stress on the rodents given nicotine. For example, restriction of water intake during pregnancy induces marked alterations in maternal-fetal fluid homeostasis and reduces birth weights in newborns (Ross and Desai, 2005). Direct tests on the behavioral effects of gestational dehydration on rats do not seem to have been published and an impact on the cognitive performance measures used in this study cannot be excluded. The nicotine-exposed offspring were also low in birth weight, and low birth weight has been associated with several neuropsychological disorders including ADHD (Casper, 2004). Further studies are therefore needed to control for these potential confounds.

Second, although it was clear that performance of the 5-CSRTT was impaired on several parameters, the long-term persistence of effects was not demonstrated and the nature of the impairments therefore remains uncertain. As task performance was not stable when impairments were seen, these effects may have involved learning processes that are not specific to attentional tasks.

\section{Conclusions}

The findings indicate a direct impact of the prenatal environment on important aspects of cognition and inhibitory control later in life. The precise mechanisms by which such long-term impacts on behavior arise remain unknown, but are likely to involve epigenetic changes induced by exposure to the environmental factors (Mill and Petronis, 2008). The preclinical data presented in this study challenge the conclusion that the observed association between ADHD and maternal smoking in pregnancy is mediated entirely by genetic effects (Thapar et al, 2009; D'Onofrio et al, 2008), by showing that direct experimental manipulation of the prenatal environment, under conditions where genetic variance is controlled by the use of the same rat strain in the experimental and control samples, leads to cognitive changes that could contribute to components of the ADHD phenotype; including impulsive responding and an increase in errors during tasks with a high attentional load. Further research is required to control for potential confounding factors; yet, these data indicate the importance of the prenatal environment for aspects of inattentive and impulsive behavior in adulthood.

\section{ACKNOWLEDGEMENTS}

The research was supported by a grant from the Wellcome Trust (079314). We are grateful to Dr Jonna Kuntsi for helpful discussions.

\section{DISCLOSURE}

Philip JE Asherson has received funding for his work on advisory boards, consultancy, or industry-sponsored educational activities from Janssen-Cilag, Eli-Lilly, Shire, and Flynn Pharma. He does not possess any relevant financial holdings. Ian P Stolerman has received compensation in the past 3 years for professional services to Institut de Recherches Servier, European Monitoring Centre for Drugs and Drug Addiction, Elsevier Science Publishers, Springer-Verlag, and the US National Institute on Drug Abuse. He does not possess any relevant financial holdings. The other authors declare no conflict of interest.

\section{REFERENCES}

Adams J (1986). Methods in Behavioral Teratology. Plenum Press: New York pp 67-97.

Ajarem JS, Ahmad M (1998). Prenatal nicotine exposure modifies behavior of mice through early development. Pharmacol Biochem Behav 59: 313-318.

Andreou P, Neale BM, Chen W, Christiansen H, Gabriels I, Heise A et al (2007). Reaction time performance in ADHD: improvement under fast-incentive condition and familial effects. Psychol Med 37: 1703-1715.

Antrop I, Roeyers H, Van Oost P, Buysse A (2000). Stimulation seeking and hyperactivity in children with ADHD. Attention Deficit Hyperactivity Disorder. J Child Psychol Psychiatry 41: 225-231.

Asherson P, Brookes K, Franke B, Chen W, Gill M, Ebstein RP et al (2007). Confirmation that a specific haplotype of the dopamine transporter gene is associated with combined-type ADHD. Am J Psychiatry 164: 674-677. 
Barkley RA, Edwards G, Laneri M, Fletcher K, Metevia L (2001). Executive functioning, temporal discounting, and sense of time in adolescents with attention deficit hyperactivity disorder (ADHD) and oppositional defiant disorder (ODD). J Abnorm Child Psychol 29: 541-556.

Bedard AC, Ickowicz A, Logan GD, Hogg-Johnson S, Schachar R, Tannock R (2003). Selective inhibition in children with attention-deficit hyperactivity disorder off and on stimulant medication. J Abnorm Child Psychol 31: 315-327.

Benowitz NL, Hukkanen J, Jacob III P (2009). Nicotine chemistry, metabolism, kinetics and biomarkers. Handb Exp Pharmacol 192: 29-60.

Bertolini A, Bernardi M, Genedani S (1982). Effects of prenatal exposure to cigarette smoke and nicotine on pregnancy, offspring development and avoidance behavior in rats. Neurobehav Toxicol Teratol 4: 545-548.

Burns MJ, Nixon GJ, Foy CA, Harris N (2005). Standardisation of data from real-time quantitative PCR methods - evaluation of outliers and comparison of calibration curves. BMC Biotechnol 5: 31 .

Cardinal RN (2006). Neural systems implicated in delayed and probabilistic reinforcement. Neural Netw 19: 1277-1301.

Casper RC (2004). Nutrients, neurodevelopment, and mood. Curr Psychiatry Rep 6: 425-429.

Castellanos FX (2001). Neural substrates of attention-deficit hyperactivity disorder. Adv Neurol 85: 197-206.

Cornelius MD, Day NL (2009). Developmental consequences of prenatal tobacco exposure. Curr Opin Neurol 22: 121-125.

D'Onofrio BM, Van Hulle CA, Waldman ID, Rodgers JL, Harden KP, Rathouz PJ et al (2008). Smoking during pregnancy and offspring externalizing problems: an exploration of genetic and environmental confounds. Dev Psychopathol 20: 139-164.

Durston S, Belle JV, Zeeuw PD (2010). Differentiating frontostriatal and fronto-cerebellar circuits in attention-deficit/hyperactivity disorder. Biol Psychiatry; e-pub ahead of print 19 October 2010; doi:10.1016/j.biopsych.2010.07.037.

Dwyer JB, Broide RS, Leslie FM (2008). Nicotine and brain development. Birth Defects Res C Embryo Today 84: 30-44.

Epstein JN, Erkanli A, Conners CK, Klaric J, Costello JE, Angold A (2003). Relations between continuous performance test performance measures and ADHD behaviors. J Abnorm Child Psychol 31: $543-554$

Epstein JN, Johnson DE, Varia IM, Conners CK (2001). Neuropsychological assessment of response inhibition in adults with ADHD. J Clin Exp Neuropsychol 23: 362-371.

Ernst M, Moolchan ET, Robinson ML (2001). Behavioral and neural consequences of prenatal exposure to nicotine. J Am Acad Child Adolesc Psychiatry 40: 630-641.

Eskenazi B, Prehn AW, Christianson RE (1995). Passive and active maternal smoking as measured by serum cotinine: the effect on birthweight. Am J Public Health 85: 395-398.

Evenden JL (1999). Varieties of impulsivity. Psychopharmacology (Berl) 146: 348-361.

Faraone SV, Biederman J, Mick E (2006). The age-dependent decline of attention deficit hyperactivity disorder: a metaanalysis of follow-up studies. Psychol Med 36: 159-165.

Faraone SV, Perlis RH, Doyle AE, Smoller JW, Goralnick JJ, Holmgren MA et al (2005). Molecular genetics of attentiondeficit/hyperactivity disorder. Biol Psychiatry 57: 1313-1323.

Franke RM, Park M, Belluzzi JD, Leslie FM (2008). Prenatal nicotine exposure changes natural and drug-induced reinforcement in adolescent male rats. Eur J Neurosci 27: 2952-2961.

Fung YK (1989). Postnatal effects of maternal nicotine exposure on the striatal dopaminergic system in rats. J Pharm Pharmacol 41: 576-578.

Gianni ML, Picciolini O, Vegni C, Gardon L, Fumagalli M, Mosca F (2007). Twelve-month neurofunctional assessment and cognitive performance at 36 months of age in extremely low birth weight infants. Pediatrics 120: 1012-1019.
Gizer IR, Ficks C, Waldman ID (2009). Candidate gene studies of ADHD: a meta-analytic review. Hum Genet 126: 51-90.

Greven U, Ronald A, Rodriguez A (2010). Non-shared environmental effects of birth weight on ADHD symptoms persist into early adolescence. A 10-year longitudinal twin study. Longit Life Course Stud 3(Suppl): 332.

Hack M (2006). Young adult outcomes of very-low-birth-weight children. Semin Fetal Neonatal Med 11: 127-137.

Hahn B, Shoaib M, Stolerman IP (2002). Nicotine-induced enhancement of attention in the five-choice serial reaction time task: the influence of task demands. Psychopharmacology (Berl) 162: 129-137.

Jauniaux E, Burton GJ (2007). Morphological and biological effects of maternal exposure to tobacco smoke on the feto-placental unit. Early Hum Dev 83: 699-706.

Johansson S, Halleland H, Halmoy A, Jacobsen KK, Landaas ET, Dramsdahl $\mathrm{M}$ et al (2008). Genetic analyses of dopamine related genes in adult ADHD patients suggest an association with the DRD5-microsatellite repeat, but not with DRD4 or SLC6A3 VNTRs. Am J Med Genet B Neuropsychiatr Genet 147B: 1470-1475.

Johnson KA, Wiersema JR, Kuntsi J (2009). What would Karl Popper say? Are current psychological theories of $\mathrm{ADHD}$ falsifiable? Behav Brain Funct 5: 15.

Klein C, Wendling K, Huettner P, Ruder H, Peper M (2006). Intrasubject variability in attention-deficit hyperactivity disorder. Biol Psychiatry 60: 1088-1097.

Kotimaa AJ, Moilanen I, Taanila A, Ebeling H, Smalley SL, McGough JJ et al (2003). Maternal smoking and hyperactivity in 8-year-old children. J Am Acad Child Adolesc Psychiatry 42: 826-833.

Kuntsi J, McLoughlin G, Asherson P (2006). Attention deficit hyperactivity disorder. Neuromolecular Med 8: 461-484.

Kuntsi J, Wood AC, Rijsdijk F, Johnson KA, Andreou P, Albrecht B et al (2010). Separation of cognitive impairments in attention deficit hyperactivity disorder into two familial factors. Arch Gen Psychiatry 67: 1159-1167.

LeSage MG, Gustaf E, Dufek MB, Pentel PR (2006). Effects of maternal intravenous nicotine administration on locomotor behavior in pre-weanling rats. Pharmacol Biochem Behav 85: 575-583.

Levin ED, Briggs SJ, Christopher NC, Rose JE (1993). Prenatal nicotine exposure and cognitive performance in rats. Neurotoxicol Teratol 15: 251-260.

Levin ED, Lawrence S, Petro A, Horton K, Seidler FJ, Slotkin TA (2006). Increased nicotine self-administration following prenatal exposure in female rats. Pharmacol Biochem Behav 85: 669-674.

Li D, Sham PC, Owen MJ, He L (2006). Meta-analysis shows significant association between dopamine system genes and attention deficit hyperactivity disorder (ADHD). Hum Mol Genet 15: 2276-2284.

Livak KJ, Schmittgen TD (2001). Analysis of relative gene expression data using real-time quantitative PCR and the 2(-Delta Delta C(T)) method. Methods 25: 402-408.

Manor I, Corbex M, Eisenberg J, Gritsenkso I, Bachner-Melman R, Tyano S et al (2004). Association of the dopamine D5 receptor with attention deficit hyperactivity disorder (ADHD) and scores on a continuous performance test (TOVA). Am J Med Genet B Neuropsychiatr Genet 127B: 73-77.

Marco R, Miranda A, Schlotz W, Melia A, Mulligan A, Muller U et al (2009). Delay and reward choice in ADHD: an experimental test of the role of delay aversion. Neuropsychology 23: 367-380.

McDonald J, Schleifer L, Richards JB, de WH (2003). Effects of THC on behavioral measures of impulsivity in humans. Neuropsychopharmacology 28: 1356-1365.

McLoughlin G, Ronald A, Kuntsi J, Asherson P, Plomin R (2007) Genetic support for the dual nature of attention deficit hyperactivity disorder: Substantial genetic overlap between the inattentive and hyperactive-impulsive components. J Abnorm Child Psychol 35: 999-1008. 
Mill J, Petronis A (2008). Pre- and peri-natal environmental risks for attention-deficit hyperactivity disorder (ADHD): the potential role of epigenetic processes in mediating susceptibility. J Child Psychol Psychiatry 49: 1020-1030.

Misener VL, Luca P, Azeke O, Crosbie J, Waldman I, Tannock R et al (2004). Linkage of the dopamine receptor D1 gene to attention-deficit/hyperactivity disorder. Mol Psychiatry 9: 500-509.

Moeller FG, Barratt ES, Dougherty DM, Schmitz JM, Swann AC (2001). Psychiatric aspects of impulsivity. Am J Psychiatry 158: 1783-1793.

Muir JL, Everitt BJ, Robbins TW (1996). The cerebral cortex of the rat and visual attentional function: dissociable effects of mediofrontal, cingulate, anterior dorsolateral, and parietal cortex lesions on a five-choice serial reaction time task. Cereb Cortex 6: 470-481.

Muneoka K, Nakatsu T, Fuji J, Ogawa T, Takigawa M (1999). Prenatal administration of nicotine results in dopaminergic alterations in the neocortex. Neurotoxicol Teratol 21: 603-609.

Murrin LC, Ferrer JR, Zeng WY, Haley NJ (1987). Nicotine administration to rats: methodological considerations. Life Sci 40: $1699-1708$.

Paloyelis Y, Asherson P, Kuntsi J (2009). Are ADHD symptoms associated with delay aversion or choice impulsivity? A general population study. J Am Acad Child Adolesc Psychiatry 48: 837-846.

Patton JH, Stanford MS, Barratt ES (1995). Factor structure of the Barratt impulsiveness scale. J Clin Psychol 51: 768-774.

Paulson RB, Shanfeld J, Vorhees CV, Sweazy A, Gagni S, Smith AR et al (1993). Behavioral effects of prenatally administered smokeless tobacco on rat offspring. Neurotoxicol Teratol 15: 183-192.

Pauly JR, Slotkin TA (2008). Maternal tobacco smoking, nicotine replacement and neurobehavioural development. Acta Paediatr 97: 1331-1337.

Pauly JR, Sparks JA, Hauser KF, Pauly TH (2004). In utero nicotine exposure causes persistent, gender-dependant changes in locomotor activity and sensitivity to nicotine in $\mathrm{C} 57 \mathrm{Bl} / 6$ mice. Int J Dev Neurosci 22: 329-337.

Paz R, Barsness B, Martenson T, Tanner D, Allan AM (2007). Behavioral teratogenicity induced by nonforced maternal nicotine consumption. Neuropsychopharmacology 32: 693-699.

Peters MA, Ngan LL (1982). The effects of totigestational exposure to nicotine on pre- and postnatal development in the rat. Arch Int Pharmacodyn Ther 257: 155-167.

Polanczyk G, de Lima MS, Horta BL, Biederman J, Rohde LA (2007). The worldwide prevalence of ADHD: a systematic review and metaregression analysis. Am J Psychiatry 164: 942-948.

Ribary U, Lichtensteiger W (1989). Effects of acute and chronic prenatal nicotine treatment on central catecholamine systems of male and female rat fetuses and offspring. J Pharmacol Exp Ther 248: 786-792.

Robbins TW (2002). The 5-choice serial reaction time task: behavioural pharmacology and functional neurochemistry. Psychopharmacology (Berl) 163: 362-380.

Rogers RD, Baunez C, Everitt BJ, Robbins TW (2001). Lesions of the medial and lateral striatum in the rat produce differential deficits in attentional performance. Behav Neurosci 115: 799-811.

Romero RD, Chen WJ (2004). Gender-related response in openfield activity following developmental nicotine exposure in rats. Pharmacol Biochem Behav 78: 675-681.

Ross MG, Desai M (2005). Gestational programming: population survival effects of drought and famine during pregnancy. $A m \mathrm{~J}$ Physiol Regul Integr Comp Physiol 288: R25-R33.

Scheres A, Dijkstra M, Ainslie E, Balkan J, Reynolds B, SonugaBarke E et al (2006). Temporal and probabilistic discounting of rewards in children and adolescents: effects of age and ADHD symptoms. Neuropsychologia 44: 2092-2103.

Sagvolden T, Aase H, Zeiner P, Berger D (1998). Altered reinforcement mechanisms in attention-deficit/hyperactivity disorder. Behav Brain Res 94: 61-71.
Schneider T, Bizarro L, Asherson PJN, Stolerman IP (2009). Impulsivity, hyperactivity, enhanced 'risk-taking' behaviour and excessive nicotine consumption in adolescent rats prenatally exposed to nicotine. Behav Pharmacol 20: S21.

Schneider T, Bizarro L, Asherson PJN, Stolerman IP (2010). Gestational exposure to nicotine in drinking water: teratogenic effects and methodological issues. Behav Pharmacol 21: 206-216.

Shea AK, Steiner M (2008). Cigarette smoking during pregnancy. Nicotine Tob Res 10: 267-278.

Slotkin TA (2004). Cholinergic systems in brain development and disruption by neurotoxicants: nicotine, environmental tobacco smoke, organophosphates. Toxicol Appl Pharmacol 198: $132-151$.

Slotkin TA, Lappi SE, McCook EC, Lorber BA, Seidler FJ (1995). Loss of neonatal hypoxia tolerance after prenatal nicotine exposure: implications for sudden infant death syndrome. Brain Res Bull 38: 69-75.

Smith KM, Bauer L, Fischer M, Barkley R, Navia BA (2005). Identification and characterization of human NR4A2 polymorphisms in attention deficit hyperactivity disorder. Am J Med Genet B Neuropsychiatr Genet 133B: 57-63.

Sorenson CA, Raskin LA, Suh Y (1991). The effects of prenatal nicotine on radial-arm maze performance in rats. Pharmacol Biochem Behav 40: 991-993.

Thapar A, Rice F, Hay D, Boivin J, Langley K, van den Bree $\mathrm{M}$ et al (2009). Prenatal smoking might not cause attention-deficit/ hyperactivity disorder: evidence from a novel design. Biol Psychiatry 66: 722-727.

Tizabi Y, Popke EJ, Rahman MA, Nespor SM, Grunberg NE (1997). Hyperactivity induced by prenatal nicotine exposure is associated with an increase in cortical nicotinic receptors. Pharmacol Biochem Behav 58: 141-146.

Uebel H, Albrecht B, Asherson P, Borger NA, Butler L, Chen W et al (2010). Performance variability, impulsivity errors and the impact of incentives as gender-independent endophenotypes for ADHD. J Child Psychol Psychiatry 51: 210-218.

Vaglenova J, Birru S, Pandiella NM, Breese CR (2004). An assessment of the long-term developmental and behavioral teratogenicity of prenatal nicotine exposure. Behav Brain Res 150: 159-170.

Vaglenova J, Parameshwaran K, Suppiramaniam V, Breese CR, Pandiella N, Birru S (2008). Long-lasting teratogenic effects of nicotine on cognition: gender specificity and role of AMPA receptor function. Neurobiol Learn Mem 90: 527-536.

Wada N, Yamashita Y, Matsuishi T, Ohtani Y, Kato H (2000). The test of variables of attention (TOVA) is useful in the diagnosis of Japanese male children with attention deficit hyperactivity disorder. Brain Dev 22: 378-382.

Waldman ID, Gizer IR (2006). The genetics of attention deficit hyperactivity disorder. Clin Psychol Rev 26: 396-432.

Willcutt EG, Doyle AE, Nigg JT, Faraone SV, Pennington BF (2005). Validity of the executive function theory of attention-deficit/hyperactivity disorder: a meta-analytic review. Biol Psychiatry 57: 1336-1346.

Williams NM, Zaharieva I, Martin A, Langley K, Mantripragada K, Fossdal $\mathrm{R}$ et al (2010). Rare chromosomal deletions and duplications in attention-deficit hyperactivity disorder: a genome-wide analysis. Lancet 376: 1401.

Winstanley CA, Dalley JW, Theobald DE, Robbins TW (2004). Fractionating impulsivity: contrasting effects of central 5-HT depletion on different measures of impulsive behavior. Neuropsychopharmacology 29: 1331-1343.

Winstanley CA, Eagle DM, Robbins TW (2006). Behavioral models of impulsivity in relation to ADHD: translation between clinical and preclinical studies. Clin Psychol Rev 26: 379-395.

Winzer-Serhan UH (2008). Long-term consequences of maternal smoking and developmental chronic nicotine exposure. Front Biosci 13: 636-649. 